\title{
PENGARUH PENCAMPURAN MINYAK SOLAR DENGAN BIODIESEL PADA NILAI ANGKA SETANA
}

\author{
Pratomo Setyadi, Cahyo Setyo Wibowo \\ e-mail : pratomo_setyadi@yahoo.com, cahyoswibowo@yahoo.com
}

\begin{abstract}
ABSTRAK
Tersedianya bahan bakar diesel fosil dalam jumlah yang besar dan murah, maka penelitian dan pemakaian minyak nabati sebagai bahan bakar diesel ditinggalkan. Terjadinya krisis suplai minyak bumi pada tahun 1973 menimbulkan kembali perhatian pada pemakaian minyak nabati sebagai bahan bakar diesel dan pada saat ini penelitian telah dilakukan secara intensif oleh berbagai lembaga riset dari berbagai penjuru dunia dengan menggunakan konsep dan teknologi yang baru.

Ruang lingkup penelitian ini adalah meliputi kajian literatur, pengambilan percontoh bahan bakar minyak diesel (minyak solar) dan biodiesel, pencampuran minyak solar dan biodieseldenganperbandingan 30:70 dan 40:60, pengujian angka setana hasil campuran pada mesin CFR F-5.

Dari hasil pengujian yang dilakukan untuk semua percontoh baik itu Biodiesel 100\%, Solar 100\% atau campurannya sama sekali tidak ada masalah dalam proses pengujian baik itu pada injektor mesin atau filter bahan bakar mada mesin uji, sedangkan untuk nilai angka setana pada campuran $10 \%$ (B-10) biodiesel cukup signifikan bisa sampai 2,1;pada campuran 20\% (B-20): 0,9; pada campuran $30 \%$ (B-30): 0,9 dan seterusnya. Peningkatan angka setana hampir linier sampai 100\% biodiesel (B-100), sehingga dapat disimpulkan bahwa Biodiesel sangat bagus untuk campuran bahan bakar minyak diesel/minyak solar sebagai peningkat angka setana/Cetana number booster I dalam pembuatan menuju minyak solar yang berkualitas tinggi dan ramah lingkungan.
\end{abstract}

Kata Kunci : biodiesel, setana,bahan bakar

\section{PENDAHULUAN}

Berbagai kegiatan pada sektor industri, transportasi, pertanian dan berbagai sektor lainnya, banyak tergantung kepada pemakaian motor diesel. Sumber bahan bakar diesel fosil dari waktu ke waktu akan berkurang, demikian juga dengan tingginya harga minyak dunia saat ini perlu bahan bakar pengganti dari sumber terbarukan yang dapat digunakan sebagai bahan bakar diesel.

Minyak nabati merupakan salah satu alternatif yang dapat digunakan baik sebagai pengganti maupun sebagai substitusi bahan bakar diesel. Sebagai bahan bakar pengganti diharapkan minyak nabati dapat menggantikan pemakaian bahan bakar diesel fosil dan sebagai substitusi bahan bakar diesel diharapkan minyak nabati dapat menggantikan sebagian bahan bakar diesel fosil atau dalam bentuk campuran dengan bahan bakar diesel fosil.

Pemakaian minyak nabati sebagai bahan bakar diesel bukanlah hal baru. Dr. Rudolf Diesel yang menciptakan motor diesel telah mempergunakan minyak kacang tanah sebagai bahan bakar untuk menjalankan mesinnya pada suatu pameran yang diadakan pada awal tahun 1900 di Paris.

Maksud dari penelitian ini adalah untuk mendorong berkembangnya penggunaan biodiesel di Indonesia untuk pengganti atau pencampur bahan bakar minyak diesel. Tujuan dari penelitian ini adalah memberikan masukan data teknis tetang salah satu kegunaan dan keunggulan karakteristik biodiesel.

\section{TINJAUAN PUSTAKA}

\subsection{Bahan Bakar Minyak Diesel}

Pembakaran pada motor diesel tidak diperlukan percikan api (busi) karena bahan bakar dinyalakan oleh panas dari udara tekan dengan demikian pembakaran dan langkah kerja terjadi. Sesuai jenisnya motor diesel dibedakan menjadi :motor diesel putaran rendah, motor diesel putaran sedang dan motor diesel putaran tinggi. Adapun jenis bahan bakarnya mempunyai karakteristik sifat fisika dan kimia yang sesuai 
dengan kebutuhannya. Di Indonesia ada beberapa macam bahan bakar minyak diesel yang ada di pasaran antara lain: industrial diesel oil (IDO), marine fuel oil (MFO), automotive diesel oil (ADO)/high speed diesel oil (HSD)/ minyak solar.

Khusus minyak solar untuk kendaraan bermotor yang beredar di Indonesia spesifikasinya mengikuti SK Dirjen Migas yang berlaku ada dua jenis yaitu minyak solar 48 dan minyak solar 51/dex yang spesifikasinya dapat dilihat pada tabel 2.1. Bahan bakar minyak diesel yang baik harus memiliki karakteristik yang meliputi antara lain viskositas yang sesuai, angka setana dan bebas dari zat-zat pengotor atau zat kimia yang merugikan sehingga dilakukan pengujian yang mengacu spesifikasi yang berlaku. Dalam penelitian ini kita membatasi pembahasan pada angka setana.

Angka setana pada bahan bakar minyak diesel menunjukkan kualitas penyalaan apabila nilai angka setana rendah akan memerlukan suhu yang sangat tinggi untuk penyalaannya, sebaliknya apabila angka setana tinggi memerlukan titik penyalaan sendiri yang lebih rendah sehingga angka setana yang lebih tinggi akan mengurangi angka detonasi di dalam mesin. Jika detonasi pada mesin terjadi cukup lama akan merusak bagian-bagian mesin atau bunyi mesin akan keras.

Tabel 2.1. SPESIFIKASI BAHAN BAKAR MINYAK JENIS MINYAK SOLAR PSO

PUBLIC SERVICE OBLIGATION (PSO)

\begin{tabular}{|c|c|c|c|c|c|}
\hline \multirow{3}{*}{ No } & & \multirow{3}{*}{ Satuan } & \multirow{2}{*}{\multicolumn{2}{|c|}{ Batasan }} & \multirow{3}{*}{$\begin{array}{c}\text { Metode Test } \\
\text { ASTM } \\
\end{array}$} \\
\hline & \multirow{2}{*}{ Karakteristik } & & & & \\
\hline & & & Min & Max & \\
\hline 1 & BialanganCetana : & & & & \\
\hline & \begin{tabular}{l|l}
- & Cetane Number \\
\end{tabular} & - & 48 & - & D $613-95$ \\
\hline & \begin{tabular}{l|l}
- & Cetane Index \\
\end{tabular} & - & 45 & - & D $4737-96 a$ \\
\hline 2 & Berat Jenis (pada suhu $15^{\circ} \mathrm{C}$ ) & $\mathrm{kg} / \mathrm{m}^{3}$ & $815^{1)}$ & 870 & D 1298 or D $4052-96$ \\
\hline 3 & Viscositas (padasuhu $40^{\circ} \mathrm{C}$ ) & $\mathrm{mm}^{2} / \mathrm{s}$ & 2,0 & 5,0 & D $445-97$ \\
\hline 4 & Kandungan Sulfur & $\% \mathrm{~m} / \mathrm{m}$ & - & 0.35 2) & D $2622-98$ \\
\hline 5 & Distilasi : & & & & D $86-99 a$ \\
\hline & $\mathrm{T} 90^{3)}$ & ${ }^{\circ} \mathrm{C}$ & - & - & \\
\hline & T95 ${ }^{3)}$ & ${ }^{\circ} \mathrm{C}$ & - & - & \\
\hline & TitikDidihAkhir & ${ }^{\circ} \mathrm{C}$ & - & - & \\
\hline 6 & TitikNyala & ${ }^{\circ} \mathrm{C}$ & 60 & - & D $93-99 c$ \\
\hline 7 & TitikTuang & ${ }^{\circ} \mathrm{C}$ & - & 18 & D 97 \\
\hline 8 & ResiduKarbon & $\% \mathrm{~m} / \mathrm{m}$ & - & 0.1 & D $4530-93$ \\
\hline 9 & Kandungan air & $\mathrm{mg} / \mathrm{kg}$ & - & 500 & D $1744-92$ \\
\hline 10 & StabilitasOksidasi & $\mathrm{g} / \mathrm{m}^{3}$ & - & - & D $2274-94$ \\
\hline 11 & KorosiBilahTembaga & merit & - & Class 1 & D $130-94$ \\
\hline 12 & Kandungan Abu & $\% \mathrm{~m} / \mathrm{m}$ & - & 0.01 & D $482-95$ \\
\hline 13 & KandunganSedimen & $\% \mathrm{~m} / \mathrm{m}$ & - & 0.01 & D 473 \\
\hline 14 & BilanganAsamKuat & $\mathrm{mg} \mathrm{KOH} / \mathrm{g}$ & - & 0 & D 664 \\
\hline 15 & BilanganAsam Total & $\mathrm{mg} \mathrm{KOH} / \mathrm{g}$ & - & 0,6 & D 664 \\
\hline
\end{tabular}




\begin{tabular}{|l|l|l|c|c|c|c|}
\hline 16 & & Partikulat & $\mathrm{mg} / \mathrm{l}$ & - & - & $\mathrm{D} 2276-99$ \\
\hline 17 & & Appearance & - & Clear and Bright & \\
\hline
\end{tabular}

\section{4 Biodiesel}

Bahan bakar yang dihasilkan dari minyak nabati antara lain disebut biodiesel yaitu merupakan senyawa ester alkil dari minyak nabati dengan alkohol yang dihasilkan melalui proses transesterifikasi/esterifikasi dan mempunyai sifat fisika mendekati minyak solar/diesel. Secara teknis disebut B100 (100\% murni biodiesel). Biodiesel dapat dimanfaatkan sebagai pencampur minyak solar atau sebagai salah satu pengganti minyak solar/minyak diesel, baik untuk bahan bakar transportasi maupun industri.

Dalam pemakaiannya minyak nabati sebagai bahan bakar diesel dapat dilakukan melalui beberapa pilihan, antara lain:

- Crude vegetable oil murni

- Campuran crude vegetable oil dengan bahan bakar diesel fosil

- $\quad$ Refined vegetable murni

- Campuran refined vegetable dengan bahan bakar diesel fosil

- Methyl/ethyl ester vegetable murni

- Campuran methyl/ethyl ester dengan bahan bakar diesel fosil

Perbedaan antara crude dan refined vegetable oil dengan bahan bakar diesel dari fosil, antara lain:

- Densitas dan viskositas lebih tinggi dari bahan bakar diesel fosil, yang mempengaruhi atomisasi bahan bakar dalam ruang bakar motor diesel. Atomisasi yang kurang baik akan menurunkan daya mesin dan menyebabkan terjadinya pembentukan deposit yang berlebihan pada ruang bakar dan bagian-bagian motor yang bersentuhan dengan hasil pembakaran.

- Temperatur distilasi menunjukkan dapat terjadi perengkahan termal pada suhu yang kemungkinan dijumpai oleh semprotan bahan bakar di dalam motor diesel pemasukan udara secara alamiah. Distilasi dihentikan sebelum titik didih akhir karena berbau tajam dan berasap.

- Nilai kalori lebih rendah dari bahan bakar diesel fosil, untuk membangkitkan $1 \mathrm{~kW}$ daya diperlukan bahan bakar nabati yang lebih banyak dari bahan bakar diesel fosil. Ini menunjukkan konsumsi bahan bakar nabati lebih tinggi dari bahan bakar fosil.

Dari penelitian-penelitian yang telah dilakukan untuk mempelajari berbagai efek pemakaian minyak nabati sebagai bahan bakar motor diesel, baik sebagai bahan bakar pengganti (diesel fuel substitute) maupun sebagai substitusi bahan bakar diesel (diesel fuel extender) menunjukkan bahwa kinerja motor yang memakai minyak nabati sebagai bahan bakar adalah dekat dengan kinerja motor diesel. Tetapi studi selanjutnya menunjukkan bahwa ada beberapa masalah praktis yang harus dipecahkan sebelum teknologi ini dapat digunakan dalam praktek. Masalah ini disebabkan oleh perbedaan dasar pada sifat-sifat fisika kimia antara minyak nabati dan bahan bakar diesel fosil. Sifat-sifat fisika dan kimia ini akan menyebabkan atomisasi minyak nabati pada sistem injeksi akan lebih jelek dari pada bahan bakar fosil.

Untuk mendapatkan kinerja yang optimum pada sistem injeksi motor diesel ada tiga pilihan yang dapat dilakukan, yaitu:

(1) Modifikasi sifat-sifat fisika dan kimia minyak nabati sesuai dengan sifat-sifat fisika dan kimia bahan bakar diesel fosil. Modifikasi peralatan injeksi untuk mendapatkan atomisasi yang memuaskan.

(3) Kombinasi dari kedua modifikasi di atas.

Kelihatannya apa yang dilakukan sekarang ini dikonsentrasikan pada pilihan (1), yaitu modifikasi sifat-sifat fisika kimia minyak nabati sebagai berikut:

1) Menggunakan campuran minyak nabati dengan bahan bakar diesel fosil.

2) Mengubah komposisi kimiawinya melalui suatu proses sederhana, seperti proses transesterifikasi. 
Cara pendekatan pemilihan pemakaian minyak nabati sebagai bahan bakar diesel adalah dengan membandingkan sifat-sifat fisika kimia minyak nabati dengan spesifikasi bahan bakar diesel fosil. Bila sifat-sifat fisika kimia minyak nabati memenuhi spesifikasi bahan bakar diesel fosil, maka minyak nabati tersebut dapat digunakan pada motor diesel sesuai

Tabel 2.2. Perbandingan Biodiesel dan Minyak Solar

\begin{tabular}{|c|c|c|}
\hline Karakteristik & Biodiesel & $\begin{array}{c}\text { Minyak } \\
\text { Solar }\end{array}$ \\
\hline Cetane number & 51 to 62 & 44 to 49 \\
\hline Lubricity & + & very low \\
\hline Biodegradability & + & - \\
\hline Toxicity & + & - \\
\hline Oxygen & $\begin{array}{l}\text { up to } \\
11 \%\end{array}$ & very low \\
\hline Aromatics & 0 & $18-22 \%$ \\
\hline Sulphur & 0 & $\begin{array}{l}0-350 \\
\mathrm{ppm}^{3}\end{array}$ \\
\hline Cloud point & - & + \\
\hline Flash point & $\begin{array}{c}300- \\
400^{0} \mathrm{~F}\end{array}$ & $125^{\circ} \mathrm{f}$ \\
\hline $\begin{array}{l}\text { Effect on natural, } \\
\text { butyl rubber }\end{array}$ & $\begin{array}{c}\text { cart } \\
\text { degrade }\end{array}$ & $\begin{array}{c}\text { no } \\
\text { impact }\end{array}$ \\
\hline
\end{tabular}

klasifikasinya. Sebaliknya bila tidak memenuhi spesifikasi bahan bakar diesel fosil, maka dapat dilakukan

pencampuran minyak nabati dengan bahan bakar diesel fosil untuk mendekati sifat-sifat fisika kimia bahan bakar diesel fosil.

Pengurangan Emisi Potential dari Campuran Biodiesel

Biodiesel, persentase campuran

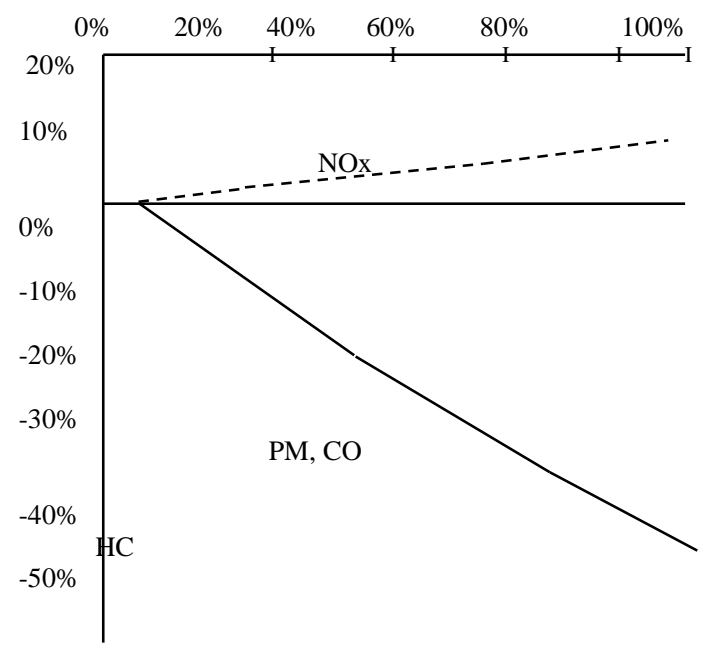

Sumber : Environmental Protection Agency (US. EPA)

Semakin besar substitusi Biodiesel NOx sedikit meningkat, sedangkan PM, CO dan $\mathrm{HC}$ menurun secara signifikan.

Salah satu keunggulan biodiesel adalah mempunyai anka setana yang cukup tinggi sehingga dalam usaha meningkatkan kualitas bahan bakar minyak diesel cukup bagus apabila salah satu karakteristik ini diteliti terus untuk mendapatkan campuarn yang tepat dan mendapatkan hasil yang maksimum. Pemerintah Indonesia

telahmenetapkanstandarmutuuntukproduk biodiesel

sehinggakonsumenakanterlindungidarisegikualitas nya. Perandingan karakteristik biodiesel dengan minyak solar dapat dilihat pada table 2.2.

\section{METODOLOGI PENELITIAN}

Alur kerja penelitian adalah gambaran umum untuk memandu peneliti dalam melakukan penelitian. Alur kerja yang akan dilakukan adalah sebagai berikut : 


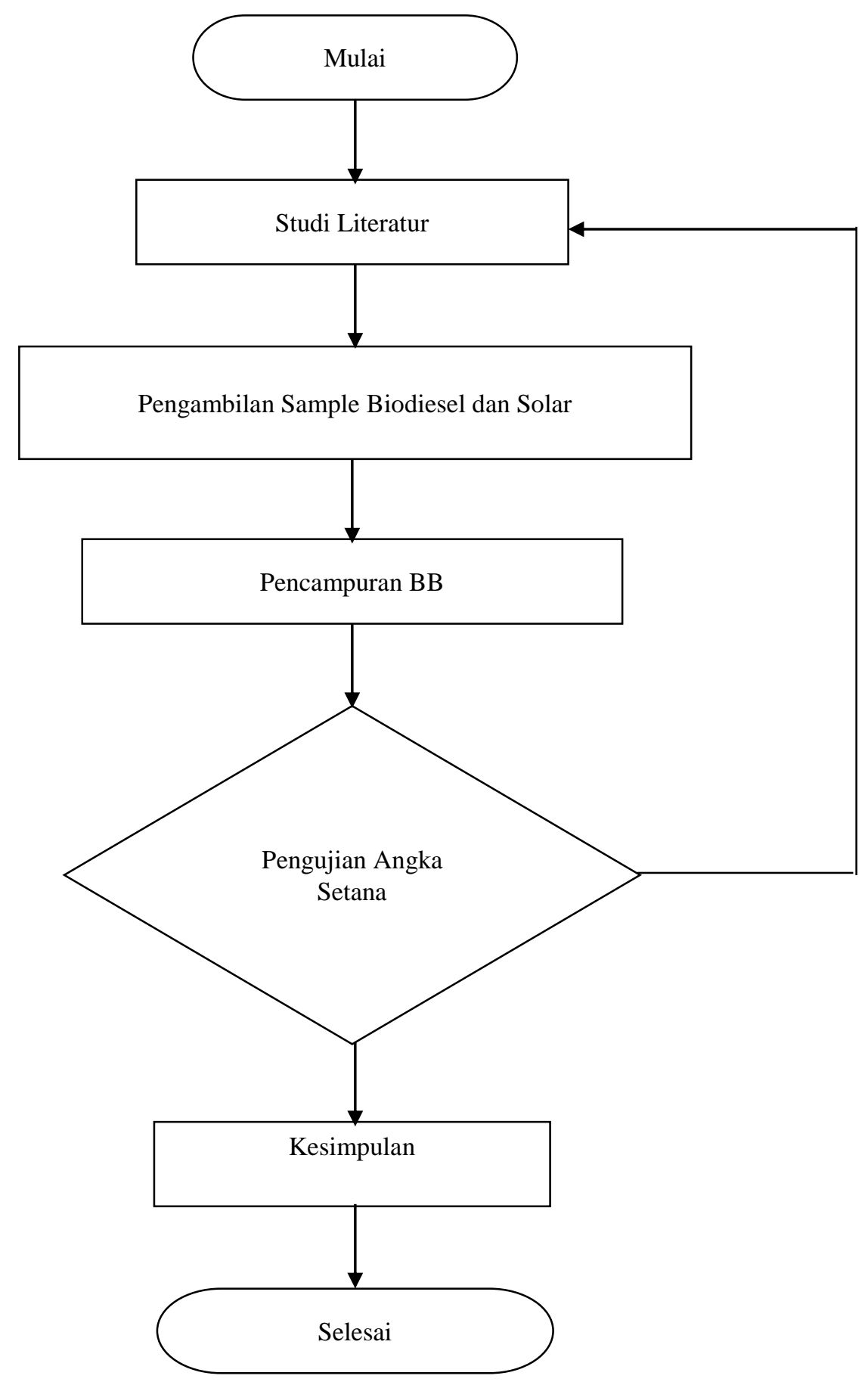

Gambar 3.1 Alur Proses Penelitian 


\section{HASIL DAN PEMBAHASAN}

\section{Hasil Uji}

Dengan menggunakan mesin uji CFR -F5 dan menggunakan metode uji ASTM D-613, untuk semua percontoh didapatkan hasil sebagai berikut :

Tabel 3.1. Hasil Pengujian Percontoh

\begin{tabular}{|c|c|l|c|}
\hline \hline $\begin{array}{c}\text { N } \\
\text { o }\end{array}$ & $\begin{array}{c}\text { Identitas } \\
\text { Percontoh }\end{array}$ & Metode Uji & Hasil \\
\hline 1 & B-100 & $\begin{array}{l}\text { ASTM D } \\
613\end{array}$ & 62,3 \\
\hline 2 & B-90 & $\begin{array}{l}\text { ASTM D } \\
614\end{array}$ & 62 \\
\hline 3 & B-80 & $\begin{array}{l}\text { ASTM D } \\
615\end{array}$ & 58,8 \\
\hline 4 & B-70 & $\begin{array}{l}\text { ASTM D } \\
616\end{array}$ & 57,9 \\
\hline 5 & B-60 & $\begin{array}{l}\text { ASTM D } \\
617\end{array}$ & 56,5 \\
\hline 6 & B-50 & $\begin{array}{l}\text { ASTM D } \\
618\end{array}$ & 54,3 \\
\hline 7 & B-40 & $\begin{array}{l}\text { ASTM D } \\
619\end{array}$ & 53,5 \\
\hline 8 & B-30 & $\begin{array}{l}\text { ASTM D } \\
620\end{array}$ & 52,1 \\
\hline 9 & B-20 & $\begin{array}{l}\text { ASTM D } \\
621\end{array}$ & 51,2 \\
\hline 10 & B-10 & $\begin{array}{l}\text { ASTM D } \\
622\end{array}$ & $\begin{array}{l}\text { ASTM D } \\
623\end{array}$ \\
\hline 11 & S-100 & 48,2 \\
\hline
\end{tabular}

Grafik 3.1. Angka setana-Prosentase campurannya

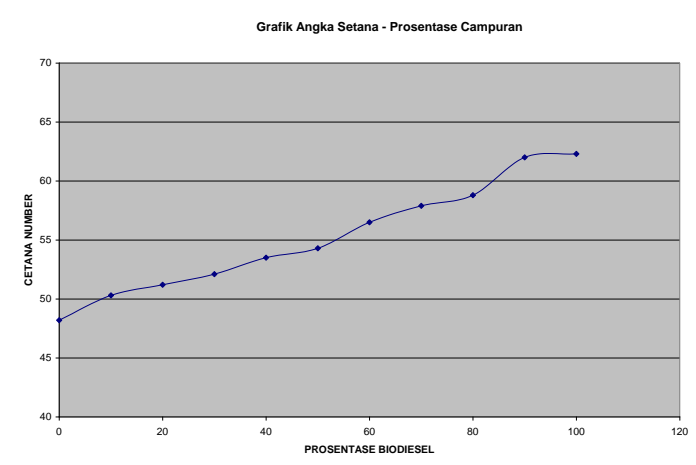

\section{Pembahasan dan Kesimpulan}

Dari hasil pengujian yang dilakukan untuk semua percontoh baik itu Biodiesel $100 \%$, Solar $100 \%$ atau campurannya sama sekali tidak ada masalah dalam proses pengujian baik itu pada injektor mesin atau filter bahan bakar mada mesin uji, sedangkan untuk nilai angka setana pada campuran $10 \%$ (B-10) biodiesel cukup siknifikan bisa sampai 2,1;pada campuran 20\% (B-20): 0,9; pada campuran 30\% (B-30): 0,9 dan seterusnya seperti terlihat di tabel dan grafik diatas. Peningkatan angka setana hampir linier sampai 100\% biodiesel (B-100), sehingga dapat disimpulkan bahwa Biodiesel sangat bagus untuk campuran bahan bakar minyak diesel/minyak solar sebagai peningkat angka setana/Cetana number booster I dalam pembuatan menuju minyak solar yang berkualitas tinggi dan ramah lingkungan. Hal ini disebabkan oleh struktur kimia dari biodiesel itu sendiri. Biodiesel juga memiliki sifat lubrikasi yang lebih baik dari minyak solar biasa, hal ini menaikkan efisiensi mesin akibat mampu mengisi celah kosong ruang antar komponen mesin serta mengurangi keausan pada mesin. Kelebihan lain nya adalah, biodiesel mengandung oksigen dalam jumlah yang cukup banyak, yang memberikan tambahan molekul oksigen dalam reaksi pembakaran. Dengan bertambahnya oksigen, maka otomatis reaksi pembakaran yang terjadi lebih sempurna dan menghasilkan pelepasan kalur dalam jumlah besar. Dari kombinasi keunggulan tersebut, maka menghasilkan perfoma mesin yang lebih baik, lebih senyap dan lebih bersih.

Hasil yang sangat baik ini bukan berarti tidak memiliki kelemahan, biodiesel yang diproduksi didalam negeri masih memiliki tingkat keasaman yang tinggi. Hal ini menyebabkan terjadinya keausan pada saluran bahan bakar dan sil karet, akibat reaksi asam. Untuk saat ini, tingkat produksi biodiesel belum mencapai nilai keekonomisan. Biodiesel juga memerlukan tekanan yang tinggi, sehingga membutuhkan material mesin yang lebih kuat. 


\section{Daftar Pustaka}

[1] Srinivasa, P. And Gopalakrishnan, K. V., Vegetable Oils and Their Methyl Ester as Fuels for Diesel Engines, Indian J. Technology, 29 (1991) 292

[2] Kusy, Paul F., Transesterification of Vegetable Oils for Fuels, Vegetable Oil Fuel, Proceedings of the International Coference on Plant and Vegetable Oils as Fuels, ASAE, (1982) 127.

[3] La Puppung, P., BeberapaMinyakNabati yang MamilikiPotensisebagaiBahan Bakar Alternatifuntuk Motor Diesel, LembaranPublikasiLemigas , 4 (1985) 34.

[4] Internal Combustion Engine Fundamentals, John B. Heywood, McGraw Hill, 1988

[5] Automotive Fuels Reference Book, Keith Owen, Trevor Coley SAE, 1995

[6] Seminar dan workshop bio-fuel DESDM 2006

[7] ASTM D 613

[8] SNI Biodiesel 